\title{
Role of poly-proline motif in HIV-2 Vpx expression
}

\author{
Ariko Miyake', Yasuyuki Miyazaki ${ }^{1}$, Mikako Fujita ${ }^{2}$, Masako Nomaguchi ${ }^{1}$ and Akio Adachi ${ }^{1 *}$ \\ ${ }^{1}$ Department of Microbiology, Institute of Health Biosciences, The University of Tokushima Graduate School, Tokushima, Japan \\ 2 School of Pharmacy, Research Institute for Drug Discovery, Kumamoto University, Kumamoto, Japan. \\ *Correspondence: adachi@basic.med.tokushima-u.ac.jp
}

Edited and reviewed by:

Hironori Sato, National Institute of Infectious Diseases, Japan

Keywords: HIV-2, SIV, Vpx, Vpr, PPM

Human and simian immunodeficiency viruses (HIV and SIVs) contain several auxiliary genes not found in other retroviruses. These genes are thought to be functionally important for optimal viral replication and persistence in infected individuals. Primate lentiviruses can be classified by the composition of these accessory genes. While viruses of the HIV typel (HIV-1) group have vif, vpr, $v p u$, and nef genes, those of the HIV-2 group carry vif, $v p x, v p r$, and nef genes (Fujita et al., 2010). Vpx protein encoded by the $v p x$ gene is unique to non-HIV-1 viruses, and is essential for viral replication in macrophages in contrast to its structural paralog Vpr (Fujita et al., 2010). The most outstanding sequence feature to distinguish Vpx from Vpr is the presence of poly-proline motif (PPM) at its C-terminal region. We have recently shown, by in vitro and in vivo assay systems, that the PPM in HIV-2 Vpx is critical for its efficient translation (Miyake et al., 2014).

Although PPM consisting of seven consecutive prolines has been demonstrated to be required for efficient HIV-2 Vpx translation, thereby acquiring viral infectivity in macrophages, the effects of PPM mutations on the degradation of $\mathrm{Vpx}$ in cells was not formally analyzed as yet (Fujita et al., 2008; Miyake et al., 2014). Therefore, in this study, we asked whether the PPM plays a role in keeping away from proteasomal and/or lysosomal degradation (Figure 1). In order to assess this, we used various expression plasmids for HIV-2 Vpx (pEF-Fvpx series) described in a previous study (Miyake et al., 2014): wild-type (WT) plasmid has the $v p x$ gene derived from HIV-2 GL-AN clone (Kawamura et al., 1994); mutants 103/4A and 106/4A have four consecutive alanine-substitutions at the site of P103-P106 and P106-P109, respectively, and have been shown to express a low/minimum level of mutant Vpx proteins in cells (Figure 1A); a negative control is a frame-shift mutant pEF-FxSt that lacks Vpx expression $(\Delta \mathrm{Vpx})$.

Various expression plasmids were transfected into human $293 \mathrm{~T}$ cells (Lebkowski et al., 1985) as described before (Adachi et al., 1986), and the amounts of WT and mutant Vpx proteins produced in cells in the absence or presence of a proteasome inhibitor MG-132 (Fujita et al., 2004; McCulley and Ratner, 2012) were comparatively examined by Western blotting (Miyake et al., 2014). A drastic reduction in Vpx expression was observed for mutants 103/4A and 106/4A, $106 / 4 \mathrm{~A}$ in particular, both in the absence

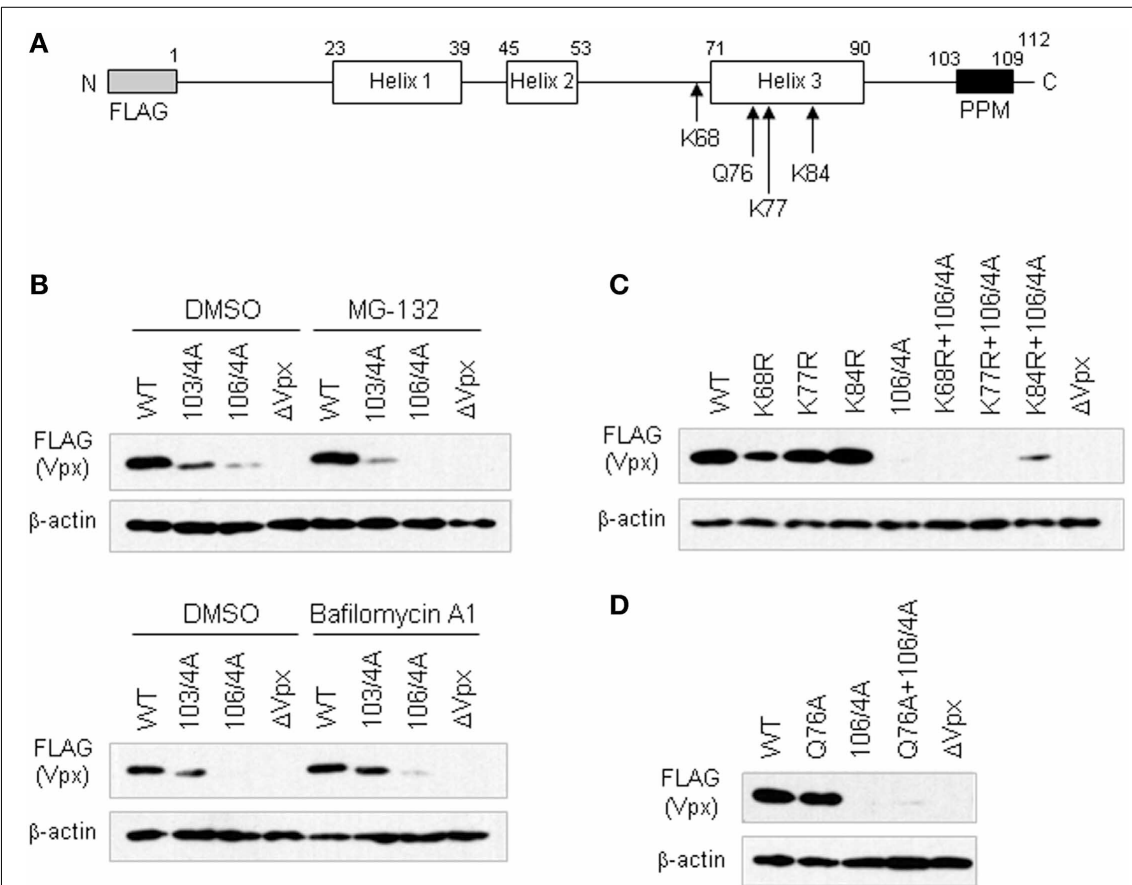

FIGURE 1 | Steady-state levels of various Vpx-PPM mutants in cells as monitored by Western blotting. (A) Structure of the FLAG-tagged HIV-2 GLAN Vpx construct. Numerals above the schema represent amino acid numbers of the $V p x$ protein. Positions of lysine and glutamine residues mutated are indicated. (B) Expression of Vpx-PPM mutants in the presence of a proteasome inhibitor MG-132 or a lysosome inhibitor Bafilomycin A1. (C) Expression of lysine-mutants with or without 106/4A mutation. (D) Expression of Q76A mutants with or without 106/4A mutation. For (B) to (D) experiments, 293T cells were transfected with the plasmids indicated, and harvested for Western blotting $24 \mathrm{~h}$ later. To examine lysosomal and proteasomal degradation processes (B), $100 \mathrm{nM}$ of BafilomycinA1 (Yoshimori et al., 1991) and 7.5 $\mu$ M of MG-132 (McCulley and Ratner, 2012) were added at 5 and $16 \mathrm{~h}$ post-transfection, respectively. WT, pEF-Fvpx; $\Delta$ Vpx, pEF-FxSt. 
and presence of MG-132 (Figure 1B). These results showed that neither of these mutants could be rescued with MG132, suggesting no involvement of the PPM in the proteasome-mediated degradation. Similarly, a lysosome inhibitor Bafilomycin A1 (Yoshimori et al., 1991) did not affect much the level of 103/4A and 106/4A in transfected 293T cells, although a small increase was observed for both mutants (Figure 1B). These results suggested that the low expression level of these PPM mutants may not be attributable to the lysosomal degradation.

Proteasomal degradation is generally triggered by the polyubiquitin modification of lysine residues in a protein. There are three lysines in the Vpx of HIV2 GL-AN clone (Khamsri et al., 2006) (Figure 1A). We generated several clones carrying mutations in these residues. Furthermore, we focused on the 76th glutamine residue (Figure 1A). This amino acid has been reported to interact with DCAF1 for formation of Cullin4-based E3 ubiquitin ligase complex to degrade an anti-HIV restriction factor SAMHD1 (Hrecka et al., 2011; Laguette et al., 2011) by proteasome (Le Rouzic et al., 2007; Srivastava et al., 2008). Mutants K68R, K77R, K84R, and Q76A with or without the 106/4A mutation were constructed as described previously (Miyake et al., 2014) (Figure 1A), and examined for their expression in transfected cells (Figures 1C,D). As shown in Figure 1C, only one clone with K84R and 106/4A mutations showed a slight enhancement in agreement with a previous report (Srivastava et al., 2008). Moreover, no significant effect was observed for a mutant carrying Q76A and 106/4A mutations (Figure 1D). These results also suggested that PPM may not be associated with the proteasome-mediated degradation.

In total, proteasomal or lysosomal degradation does not account for the extremely low expression level of $\mathrm{Vpx}$ exhibited by the PPM mutants. This is consistent with our previous conclusion that PPM is critical for efficient translation of Vpx (Miyake et al., 2014). Molecular mechanism by which PPM enhances Vpx translation to a remarkable extent needs to be determined.

\section{ACKNOWLEDGMENTS}

This study was supported in part by a grant from the Ministry of Health, Labour and Welfare of Japan (Research on HIV/AIDS project no. H24-005).

\section{REFERENCES}

Adachi, A., Gendelman, H. E., Koenig, S., Folks, T., Willey, R., Rabson, A., et al. (1986). Production of acquired immunodeficiency syndrome-associated retrovirus in human and nonhuman cells transfected with an infectious molecular clone. J. Virol. 59, 284-291.

Fujita, M., Akari, H., Sakurai, A., Yoshida, A., Chiba, T., Tanaka, K., et al. (2004). Expression of HIV-1 accessory protein Vif is controlled uniquely to be low and optimal by proteasome degradation. Microbes Infect. 6, 791-798. doi: 10.1016/j.micinf.2004.04.011

Fujita, M., Otsuka, M., Nomaguchi, M., and Adachi, A. (2008). Functional region mapping of HIV2 Vpx protein. Microbes Infect. 10, 1387-1392. doi: 10.1016/j.micinf.2008.08.005

Fujita, M., Otsuka, M., Nomaguchi, M., and Adachi, A. (2010). Multifaceted activity of HIV Vpr/Vpx proteins: the current view of their virological functions. Rev. Med. Virol. 20, 68-76. doi: 10.1002/rmv.636

Hrecka, K., Hao, C., Gierszewska, M., Swanson, S. K., Kesik-Brodacka, M., Srivastava, S., et al. (2011). $\mathrm{Vpx}$ relieves inhibition of HIV-1 infection of macrophages mediated by the SAMHD1 protein. Nature 474, 658-661. doi: 10.1038/nature10195

Kawamura, M., Sakai, H., and Adachi, A. (1994). Human immunodeficiency virus Vpx is required for the early phase of replication in peripheral blood mononuclear cells. Microbiol. Immunol. 38, 871-878. doi: 10.1111/j.1348-0421.1994.tb02140.x

Khamsri, B., Murao, F., Yoshida, A., Sakurai, A., Uchiyama, T., Shirai, H., et al. (2006). Comparative study on the structure and cytopathogenic activity of HIV Vpr/Vpx proteins. Microbes Infect. 8, 10-15. doi: 10.1016/j.micinf.2005.05.020

Laguette, N., Sobhian, B., Casartelli, N., Ringeard, M., Chable-Bessia, C., Segeral, E., et al.
(2011). SAMHD1 is the dendritic- and myeloid-cell-specific HIV-1 restriction factor counteracted by Vpx. Nature 474, 654-657. doi: 10.1038/nature 10117

Lebkowski, J. S., Clancy, S., and Calos, M. P. (1985). Simian virus 40 replication in adenovirus-transformed human cells antagonizes gene expression. Nature 317, 169-171. doi: 10.1038/ $317169 \mathrm{a} 0$

Le Rouzic, E., Belaidouni, N., Estrabaud, E., Morel, M., Rain, J. C., Transy, C., et al. (2007). HIV1 Vpr arrests the cell cycle by recruiting DCAF1/VprBP, a receptor of the Cul4-DDB1 ubiquitin ligase. Cell Cycle 6, 182-188. doi: 10.4161/cc.6. 2.3732

McCulley, A., and Ratner, L. (2012). HIV-2 viral protein $\mathrm{X}(\mathrm{Vpx})$ ubiquitination is dispensable for ubiquitin ligase interaction and effects on macrophage infection. Virology 427, 67-75. doi: 10.1016/j.virol.2012.02.002

Miyake, A., Fujita, M., Fujino, H., Koga, R., Kawamura, S., Otsuka, M., et al. (2014). Polyproline motif in HIV-2 Vpx is critical for its efficient translation. J. Gen. Virol. 95, 179-189. doi: 10.1099/vir.0.057364-0

Srivastava, S., Swanson, S. K., Manel, N., Florens, L., Washburn, M. P., and Skowronski, J. (2008). Lentiviral Vpx accessory factor targets $\mathrm{VprBP} / \mathrm{DCAF} 1$ substrate adaptor for cullin 4 E3 ubiquitin ligase to enable macrophage infection. PLoS Pathog. 4:e1000059. doi: 10.1371/journal.ppat.1000059

Yoshimori, T., Yamamoto, A., Moriyama, Y., Futai, M., and Tashiro, Y. (1991). Bafilomycin A1, a specific inhibitor of vacuolar-type $\mathrm{H}(+)$-ATPase, inhibits acidification and protein degradation in lysosomes of cultured cells. J. Biol. Chem. 266, 17707-17712.

Received: 13 January 2013; accepted: 14 January 2014; published online: 28 January 2014.

Citation: Miyake A, Miyazaki Y, Fujita M, Nomaguchi $M$ and Adachi A (2014) Role of poly-proline motif in HIV-2 Vpx expression. Front. Microbiol. 5:24. doi: 10.3389/fmicb.2014.00024

This article was submitted to Virology, a section of the journal Frontiers in Microbiology.

Copyright (c) 2014 Miyake, Miyazaki, Fujita, Nomaguchi and Adachi. This is an open-access article distributed under the terms of the Creative Commons Attribution License (CC BY). The use, distribution or reproduction in other forums is permitted, provided the original author(s) or licensor are credited and that the original publication in this journal is cited, in accordance with accepted academic practice. No use, distribution or reproduction is permitted which does not comply with these terms. 